\title{
In Memoriam: Maria del Rosario Ruiz (1950 - 2017)
}

\author{
Michelle Ennis Soreth ${ }^{1}$ - Chata A. Dickson ${ }^{2}$. \\ Christeine M. Terry ${ }^{3}$
}

Published online: 29 November 2017

(C) Association for Behavior Analysis International 2017

Maria del Rosario Ruiz, PhD, BCBA-D, Professor Emerita of Psychology at Rollins College, died in her home during the early morning hours of August 15, 2017, after a yearlong battle with metastatic cancer. Maria was the complete behavior analyst. Her life's work balanced her commitment to the experimental analysis of behavior (EAB), to radical behaviorism, and to the application of behavior analysis in service to individual consumers and humanity at large. Sharing the science, philosophy, and practice of behavior analysis with others was one of the great joys of her life.

Maria was born in Havana, Cuba, in 1950. She was a young child during the Cuban Revolution (1953-1959). As Fidel Castro established his communist regime in Cuba in the early 1960s and fear of indoctrination spread across the island, over 14,000 children were sent to the United States by their parents as part of Operación Pedro Pan, the largest mass exodus of unaccompanied minors ever recorded in the Western Hemisphere. At age 11, Maria was sent to Miami and lived in a foster network for 3 years until her parents were able to secretly leave Cuba and join her in the United States. After her parents - both physicians - obtained U.S. citizenship and passed their medical board exams, the family moved to Orlando in 1965. Maria soon began her undergraduate studies at the University of Florida (UF), where she would remain throughout her graduate education, completing an MEd in special education, an MA in psychology, and a $\mathrm{PhD}$ in psychology.

\footnotetext{
Michelle Ennis Soreth

soreth@rowan.edu

Chata A. Dickson

cdickson@necc.org

Christeine M. Terry

christeineterry@gmail.com
}

1 Psychology Department, Rowan University, 201 Mullica Hill Road, Glassboro, NJ 08028, USA

2 New England Center for Children, 33 Turnpike Road, Southborough, MA 01772, USA

3 Private Practice, Seattle, WA, USA 
Throughout her training and career, Maria was unbound by the branches of study that shape the increasingly specialized careers of behavior analysts today. Mentored by Hank Pennypacker, Maria was trained in the strong EAB tradition at UF and worked on a variety of research projects, including those involving self-injury (Ruiz, 1985), stimulus overselectivity (Ruiz, 1983b), fluency-based instruction (Ruiz, 1983a), and contingency contracting in the treatment of individuals with drug abuse (Boudin et al., 1977). Maria continued to sharpen her EAB skills and expanded further into behavioral pharmacology in a postdoctoral position with Joe Brady at Johns Hopkins University (Foltin et al., 1986).

Prior to completing her dissertation at UF, Maria returned to the Orlando area and accepted a position at Rollins College, a small private liberal arts college in idyllic Winter Park, Florida. Rollins is Florida's oldest institution of higher education, and although the institution has been coeducational since its inception in 1885, Maria became the first female faculty member in the psychology department when she arrived in 1980. Rollins would become the environment in which Maria would thrive, setting in place the variables that would lead to what would arguably become her greatest contributions to our field: (a) her conceptual analyses (most notably those on the alliance between feminism and the philosophy of behavior analysis); and (b) the undergraduate students she mentored, several of whom went on to earn PhDs, specializing in a wide array of applications of behavior analysis that are largely reflective of Maria's own values.

The scholarly works for which Maria has been most recognized are her conceptual analyses, particularly those involving relations and natural alliances between radical behaviorism and feminism, and the implications of this work for effectively enacting social change. Her first major paper on the topic was a groundbreaking piece published in Psychology of Women Quarterly (Ruiz, 1995). In the article, which was written primarily for an audience of feminist psychologists, Maria argued that radical behaviorism's appeal to a contextual understanding of human behavior was well allied with a feminist epistemology grounded in the experiences of women and other marginalized groups. Behavior analysis, she argued, offered an understanding of human behavior that moved away from the personalization and pathologization of behavior patterns that feminists had also argued had clear determinants in oppressive sociopolitical contingencies, institutions, and systems. Several years later, in an article published in The Behavior Analyst (Ruiz, 1998), Maria identified personal agency as the "illusive dweller," a construct that plagues feminist theory and limits effective action. In her view, behavior analysts had much to offer feminist scholars and activists in our understanding of agency as action in context rather than a quality of the individual. Although she noted that feminist scholarship, politics, and activism would continue to grow without contributions from behavior analysts, such an alliance had the potential to liberate and strengthen both disciplines. In an experimental extension of her theoretical work, Maria later collaborated with Bryan Roche of the National University of Ireland and his colleagues to develop the Function Acquisition Speed Task (FAST), a behavior-analytic reconstruction of the implicit association task (IAT; O'Reilly et al., 2013; O'Reilly, Roche, Ruiz, Tyndall, \& Gavin, 2012). Maria viewed the FAST as a way to experimentally evaluate the development of prejudiced verbal behavior and demonstrate that discriminatory behavior could be learned and potentially remediated using behavior-analytic principles. 
Although Maria's conceptual contributions were considerable, her greatest impact on the field may ultimately be through her legacy as a teacher and mentor. As a teacher, Maria arranged learning opportunities in diverse areas of behavior analysis, including exposing undergraduates to the personalized system of instruction (PSI), the EAB animal laboratory, and applied behavior analysis with children and adults with developmental disabilities. She arranged a winter intersession term in Mexico at Los Horcones, spending several weeks with a group of undergraduate students as they lived as part of the Walden Two community. She always made her students feel as though they had something valuable to share, and in so doing arranged the conditions under which her students found their own voices and cultivated their unique contributions. Upon reflecting on her pedagogy, Maria viewed her role as a teacher as that of a facilitator:

In very general terms I view the process of teaching and learning as guided discovery. With experience in the field, the instructor assumes the role of guide and facilitates for students the exploration of exciting new terrain. An overriding goal in this process is to equip the students with exploratory skills that they can apply in future journeys, and ultimately allow them to become their own guides in the process. (M. Ruiz, personal communication, 1994)

Maria's students quickly became their own guides as she launched the careers of at least seven $\mathrm{PhDs}$ in behavior analysis as well as the careers of numerous BCBAs, all while teaching at what had been almost exclusively an undergraduate institution throughout her academic career. Her undergraduate students went on to graduate training with giants in behavior analysis, including Murray Sidman, Linda Parrott Hayes, Ogden Lindsley, Steven C. Hayes, Philip N. Hineline, Kennon A. Lattal, Elbert Q. Blakely, William V. Dube, Timothy R. Vollmer, Robert J. Kohlenberg, and Henry S. Pennypacker. Maria's influence is evident in the diverse areas of expertise of her students, including innovative applications of fluency-based instruction (Kimberly Nix Berens and Nicholas M. Berens), translational research (Chata A. Dickson), clinical behavior analysis (Christeine M. Terry), dissemination of behavior analysis (Michelle Ennis Soreth), and the application of behavior analysis to enhance the quality of life of children in foster care (Cristina M. Whitehouse). In her final years at Rollins, Maria's love of teaching and commitment to the continued success of behavior analysis culminated in one of her proudest accomplishments: establishing the Master's Program in Applied Behavior Analysis and Clinical Science (ABACS) at Rollins College.

In the fall of 1981, as Maria was completing her dissertation, B. F. Skinner visited the UF campus and asked, "Why are we not acting to save the world?" (Pennypacker, 1986; Skinner, 1987). Maria's career was largely an answer to this call to action. Influenced by the personal challenges she had faced and the conceptual alliances she established with feminist scholars, Maria became a dedicated advocate for marginalized groups, including women, immigrants, individuals with disabilities, and the LGBT community. As a licensed psychologist and founder of a behavior-analytic center for children with autism, she championed the right to effective treatment for those who receive behavior-analytic services (Van Houten et al., 1988), including individuals with developmental disabilities, substance use disorders, and mental health conditions. She had grown to view behavior-analytic science as a form of political activism, with the 
ability to enact effective change and the potential to expand our sense of community and human solidarity (Ruiz \& Roche, 2007). Maria was the living embodiment of her work: a complex synthesis of behavior analysis, feminism, and social justice advocacy.

During her long illness, Maria carefully planned her end-of-life transition, including a specific request that her vast academic book collection be gifted to her students. As we wept and awed together over her handwritten notes in the margins of the classic behavior-analytic texts and her framed standard celeration charts signed by the pioneers of our science, I spotted a small ceramic plaque that bluntly read "No whining." I fondly remembered seeing it the first time I walked into Maria's office as an undergraduate student many years ago and quickly identifying that this professor was the real deal - a powerful female role model who was simultaneously a scientist, an activist, and an advocate. I slowly slid the plaque off the table and, upon clutching it in the palm of my hand, said to myself, There is no time for anything except effective action. One of Maria's greatest gifts was showing us the value of dedicating our lives to do all we can to save the world in the short time we are here. As we reflect on her temporally extended legacy that will continue to influence behavior analysis for generations to come, we recognize how incredibly fortunate we are to have Maria as our guide.

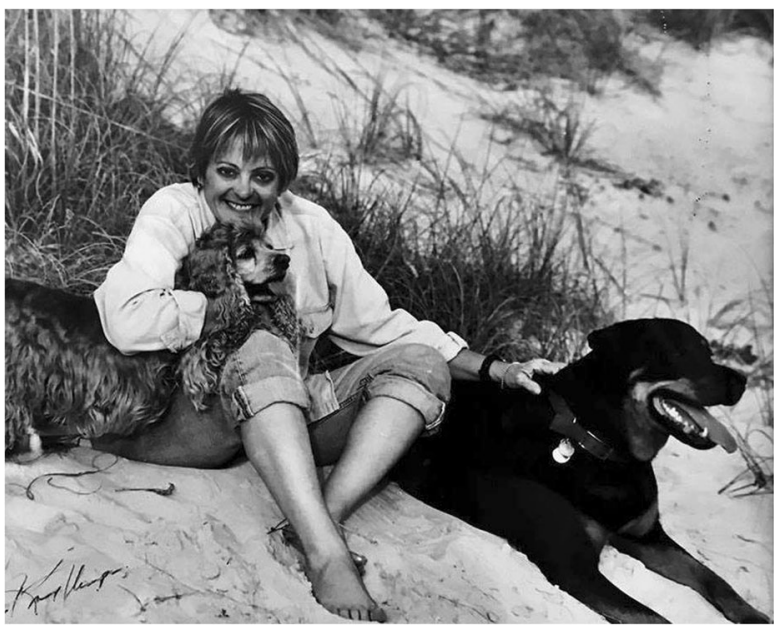

\section{References}

Boudin, H. M., Valentine, V. E., Inghram, R. D., Brantley, J. M., Ruiz, M. R., Smith, G. G., et al. (1977). Contingency contracting with drug abusers in the natural environment. International Journal of the Addictions, 12, 1-16.

Foltin, R. W., Fischman, M. W., Nellis, M. J., Bernstein, D. J., Ruiz, M. R., \& Brady, J. V. (1986). Marijuana effects and behavioral contingencies. NIDA Research Monograph Series, 67, 355-361.

O'Reilly, A., Roche, B., Gavin, A., Ruiz, M. R., Ryan, A., \& Campion, G. (2013). A function acquisition speed test for equivalence relations (FASTER). The Psychological Record, 63, 707-724.

O'Reilly, A., Roche, B., Ruiz, M., Tyndall, I., \& Gavin, A. (2012). The Function Acquisition Speed Test (FAST): a behavior analytic implicit test for assessing stimulus relations. The Psychological Record, 62, 507-528.

Pennypacker, H. S. (1986). The challenge of technology transfer: buying in without selling out. The Behavior Analyst, 9, 147-156. 
Ruiz, M. R. (1983a, May). Integrating a personalized system of instruction (PSI) track into a team-taught introduction to psychology course. Paper presented at the ninth annual meeting of the Association for Behavior Analysis, Milwaukee, WI.

Ruiz, M. R. (1983b, May). Repeated acquisitions of discriminations of compound vs. single element cues by developmentally delayed children. Paper presented at the ninth annual meeting of the Association for Behavior Analysis, Milwaukee, WI.

Ruiz, M. R. (1985, September). Physical restraints as positive and negative reinforcers in the treatment of selfinjurious behavior. Paper presented at the fifth annual meeting of the Florida Association for Behavior Analysis, Tampa, FL.

Ruiz, M. R. (1995). B. F. Skinner's radical behaviorism: historical misconstructions and grounds for feminist reconstructions. Psychology of Women Quarterly, 19, 161-179.

Ruiz, M. R. (1998). Personal agency in feminist theory: evicting the illusive dweller. The Behavior Analyst, $21,179-192$.

Ruiz, M. R., \& Roche, B. (2007). Values and the scientific culture of behavior analysis. The Behavior Analyst, 30, 1-16.

Skinner, B. F. (1987). Upon further reflection. Englewood Cliffs: Prentice Hall.

Van Houten, R., Axelrod, S., Bailey, J. S., Favell, J. E., Foxx, R. M., Iwata, B. A., \& Lovaas, O. I. (1988). The right to effective behavioral treatment. Journal of Applied Behavior Analysis, 21, 381-384. 